\title{
A note on metric nonlinear connections on the cotangent bundle
}

\author{
LIVIU POPESCU and RADU CRIVEANU
}

\section{ABSTRACT.}

In the present paper we continue the investigation of nonlinear connections started in [16]. The problem of metrizability of the nonlinear connection on the cotangent bundle is studied. Using the dynamical covariant derivative induced by a regular vector field, we find the coefficients of a metric nonlinear connection. For the particular case of a Hamiltonian space we prove that the canonical nonlinear connection is a unique metric and symmetric nonlinear connection.

\author{
UNIVERSITY OF CRAIOVA \\ FACULTY OF ECONOMICS \\ DEPARTMENT OF MATHEMATICS AND STATISTICS \\ AL. I. CuZA 13, 200585 CRAIOVA, ROMANiA \\ E-mail address: liviupopescu@central.ucv.ro, liviunew@yahoo.com \\ E-mail address: raducriv@yahoo.com
}

